\title{
Is Radiation Necessary for Treatment of Non-Hodgkin's Lymphoma of Bone? Clinical Results With Contemporary Therapy
}

\author{
Ishaq Ibrahim BS, Bryan D. Haughom MD, \\ Yale Fillingham MD, Steven Gitelis MD
}

Published online: 21 April 2015

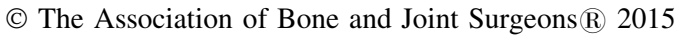

\begin{abstract}
Background Non-Hodgkin's lymphoma (NHL) of bone is a rare musculoskeletal malignancy accounting for fewer than $7 \%$ of bone cancers. Traditionally, we have treated patients who have NHL of bone with chemotherapy and radiation therapy, but the role of radiotherapy in disease management and patient functional outcomes after treatment have not been well studied. We investigated the survival advantage of radiotherapy in a large cohort of patients with NHL of bone and assessed associated patient complications of radiotherapy.
\end{abstract}

Each author certifies that he, or a member of his immediate family, has no funding or commercial associations (eg consultancies, stock ownership, equity interest, patent/licensing, arrangements, etc) that might pose a conflict of interest in connection with the submitted article.

All ICMJE Conflict of Interest Forms for authors and Clinical Orthopaedics and Related Research ${ }^{\mathbb{R}}$ editors and board members are on file with the publication and can be viewed on request.

Clinical Orthopaedics and Related Research ${ }^{\mathbb{R}}$ neither advocates nor endorses the use of any treatment, drug, or device. Readers are encouraged to always seek additional information, including FDA approval status, of any drug or device before clinical use. Each author certifies that his or her institution approved the human protocol for this investigation, that all investigations were conducted in conformity with ethical principles of research, and that informed consent for participation in the study was obtained.

This work was performed at Rush University Medical Center, Chicago, IL, USA.

I. Ibrahim ( $\square)$

Rush Medical College, Rush University, 600 S Paulina Street,

Chicago, IL 60612, USA

e-mail: iibrahim005@gmail.com

B. D. Haughom, Y. Fillingham, S. Gitelis Department of Orthopaedic Surgery, Rush University Medical Center, Chicago, IL, USA
Questions/purposes The objective of this study was to compare patients treated for NHL of bone with and without radiation in terms of (1) overall survival; (2) pretreatment complications; (3) posttreatment complications; and (4) functional outcomes using the Musculoskeletal Tumor Society (MSTS) score.

Methods A retrospective analysis of all patients with biopsy-proven NHL of bone diagnosed at our institution between 1985 and 2013 was undertaken; 70 patients met our criteria for inclusion with minimum followup of 6 months (median, 55 months; range, 10-219 months). Overall survival at 5 and 10 years was estimated and compared between two groups of patients: one group treated with systemic therapy alone (chemotherapy, rituximab; 46 patients [66\%]) and the other with combined modality therapy (systemic therapy and radiotherapy; 24 patients [34\%]). During the period in question, indications for radiotherapy included bulky disease, an abbreviated course of systemic therapy, and an incomplete response to systemic therapy. Patients not meeting these criteria generally received systemic therapy alone. With the available sample size, it was estimated that a difference in survival of approximately $30 \%$ would have to be present for detection with $80 \%$ power $(\alpha=0.05, \beta=0.2, \mathrm{n}=70, \Delta=30 \%)$. Pretreatment and posttreatment complications occurring in both patient groups were retrospectively reviewed with special emphasis on fracture healing after treatment. MSTS scores were obtained for 45 patients with appendicular tumors at a median followup of 42 months (range, 10-215 months).

Results With the data available, no difference in KaplanMeier survivorship was observed between patients treated with and without radiation at 5 years $(98 \%$; $95 \%$ confidence interval [CI], $93 \%-100 \%$ versus $95 \%$; $95 \%$ CI, $85 \%-100 \%$; $\mathrm{p}=0.281$ ). Patients who were treated with radiation were 
more likely to experience problems with fracture healing (relative risk [RR], 12.8; 95\% CI, 1.8-89.8; $\mathrm{p}=0.01$ ). Similarly, patients treated with radiation were at a higher risk for fracture in the posttreatment period (five of 24 versus no radiation zero of 46; RR, 20.7; 95\% CI, 1.2-359.0; $\mathrm{p}=0.0375)$. MSTS scores were poorer in patients treated with radiation $(75 \%$ versus $91 \% ; \mathrm{p}=0.034)$ attributable in part to a higher incidence of bony complications in this group after treatment.

Conclusions Based on the numbers of patients in our study, we could not demonstrate a survival advantage with radiation use. Rather, radiotherapy may be associated with orthopaedic complications occurring during and after treatment. Larger, prospective studies are necessary to definitively establish whether radiation is necessary for the treatment of patients with lymphoma of bone.

Level of Evidence Level III, therapeutic study.

\section{Introduction}

Non-Hodgkin's lymphoma (NHL) of bone is a rare musculoskeletal malignancy accounting for fewer than $7 \%$ of bone cancers [49]. NHL of bone affects patients of all ages but displays a predisposition for older adults (aged $\geq 60$ years) [29]. Progressive "bone pain" is the most common presenting symptom; however, the disease may be unrecognized until complications such as pathologic fracture arise. Historically, bone lymphomas, originally termed "reticulum-cell sarcoma," were treated with surgical resection and radiotherapy [34, 50]. The sensitivity of bone lymphomas to nonoperative therapies, primarily chemotherapy with cyclophosphamide, doxorubicin, vincristine, and prednisone (CHOP), in recent decades has obviated the need for surgical resection in most cases. The evolution in care has been paralleled by substantial improvements in patient survival. More recently, outcomes have been bolstered by the addition of rituximab to systemic therapy regimens (R-CHOP) with multiple studies reporting improvements in patient overall (OS) and disease-free survival [1, 39, 41].

NHL of bone remains an uncommon and incompletely understood clinical entity. Because of its relative rarity, many aspects of management remain controversial [16]. At present it is not known if radiotherapy is crucial in management or if patients can be sufficiently treated with systemic therapy alone [42]. Radiation has known toxicity in bone including risk for posttreatment fracture, abnormal healing, and physeal injury in children [7, 15, 19, 24, 25, 51]. Therefore, a better understanding of the complications that may arise in those treated with radiation is important to optimizing care of these patients. Finally, patient functional outcomes using a validated scoring method have not been previously studied in patients with NHL in the appendicular skeleton. With the aim of better understanding the clinical features of NHL of bone, including the efficacy and morbidity risk of contemporary therapies, we examined 70 patients with NHL of bone diagnosed at our tertiary care institution between 1985 and 2013.

The objective of this study was to compare patients treated for NHL of bone with and without radiation in terms of (1) OS; (2) pretreatment complications; (3) posttreatment complications; and (4) functional outcomes using the Musculoskeletal Tumor Society (MSTS) score.

\section{Patients and Methods}

After institutional review board approval, we conducted a retrospective study of all patients with NHL of bone diagnosed at our institution between 1985 and 2013. The departments of pathology and hematology/oncology were queried to identify cases of bone lymphoma diagnosed at our institution between 1985 and 2013. Criteria for patient inclusion in our study were biopsy-proven NHL occurring in bone and a minimum clinical followup of 6 months [14, 16]. Criteria for exclusion included (1) unclear diagnosis; (2) diagnosis of Hodgkin's lymphoma; and (3) diagnosis of T-cell lymphoma.

Medical records were reviewed for patient age, sex, race/ethnicity, biopsy technique, histopathology, lymphoma site, presenting symptoms, imaging, staging, treatment, and orthopaedic complications. Typical staging workups included a bone scan, CT of the chest, abdomen, and pelvis, bone marrow biopsy, and positron emission tomography (PET; 40 patients) or gallium scan. Records were reviewed for chemotherapy regimen, use of rituximab, consolidative radiotherapy, and patient response to treatment. Treatment and followup were instituted by the treating medical oncologists. Routine indications for consolidative radiotherapy included (1) the presence of bulky disease; (2) treatment with an abbreviated course of systemic therapy; and (3) incomplete response to induction therapy (eg, persistent PET activity after completion of systemic therapy). Seventy patients were treated with systemic therapy and 24 of 70 patients (34\%) underwent consolidation therapy with external beam radiation (mean dose, 39 Gy; range, 30-54 \pm 6 ). Pretreatment complications, posttreatment complications, and indications for surgery were also reviewed. Fracture outcomes were reviewed for evidence of healing, delayed union, nonunion, and malunion. Variability exists in the definitions of fracture healing [6]; for the purpose of our study, delayed union was defined as union after 6 months and nonunion was defined as failure of union by 9 months [18, 47]. Union times for pretreatment fractures were estimated from the 
date the patient completed three cycles of systemic therapy. Union times for posttreatment fractures were estimated from the date of detection. Healing with nonanatomic alignment was considered malunion.

Patients with primary and secondary lymphoma of bone (PLB, SLB) were included in our study. Differentiation can be challenging and was based on guidelines adapted from the World Health Organization ([49]; Table 1). Bone marrow involvement did not preclude classification as PLB, but indicated advanced disease [1, 43]. Patients with a history of nonosseous lymphoma were considered to have SLB unless histopathology was inconsistent with secondary disease. Patients were categorized into one of two treatment groups: those treated with systemic therapy alone (chemotherapy, rituximab) and those treated with combined modality therapy (CMT; systemic therapy and radiotherapy). Functional evaluation was completed at the conclusion of the study period for all living patients with appendicular tumors using the MSTS scoring system [20]. Scores were available for 45 patients (87\% [45 of 52]) at a median followup of 42 months (range, 10-215 months). Comparisons were made on the basis of treatment group, limb involvement (upper extremity [UE] versus lower extremity [LE]), fracture at presentation, and secondary complications. Ten patients with appendicular lesions, including four with posttreatment complications, died and could not be evaluated (16\% [10 of 62]).

Treatment groups were compared for differences in demographic features, lymphoma presentation site (weightbearing versus nonweightbearing bones), extent of disease (localized versus advanced), histopathologic subtype (diffuse large B-cell lymphoma [DLBCL] versus indolent lymphoma), primary compared with secondary disease, and systemic therapy (use of rituximab and use of an anthracycline-based chemotherapy regimen; Table 2). Localized disease was defined as lymphoma limited to a single bony site with or without involvement of the regional nodes, a definition consistent with Stage 1E and 2E disease per the Ann Arbor staging system [11]. Patients with polyostotic disease, diffuse lymphadenopathy, visceral involvement, or involvement of the bone marrow were considered to have advanced disease (Stages $3 \mathrm{E}$ and 4E). Indolent lymphomas included follicular lymphoma, marginal zone lymphoma, small lymphocytic lymphoma, and Waldenström macroglobulinemia.

The records of 99 patients with newly diagnosed lymphoma of bone were screened (Fig. 1). Of 99 patients, five met criteria for exclusion $(5 \% ;<6$ months clinical followup, $\mathrm{n}=4$; $\mathrm{T}$-cell lymphoma, $\mathrm{n}=1$ ) and 22 patients (22\%) with deficient records could not be analyzed. In addition, two patients $(2 \%)$ who were not treated were not included in our analysis. The final study population consisted of 42 men $(60 \%)$ and 28 women $(40 \%)$ who met the criteria for inclusion (Table 2). None of these patients had been lost to followup. Patient mean age at diagnosis was 54 years (range, $16-81 \pm 18$ years). Most patients were white and of non-Hispanic ethnicity $(\mathrm{n}=49$ [70\%]). Sixtytwo patients presented with appendicular tumors $(89 \%$; $\mathrm{LE}=39, \mathrm{UE}=23$ ). Six patients presented with tumors in the spine and two with tumors in the skull. Most tumors occurred in the long bones $(n=42$ [60\%]; Table 3$)$. The majority of patients had pain at the site of disease and 23 (33\%) had B symptoms at presentation (fever, chills, night sweats, or weight loss). The most common histopathologic diagnosis was DLBCL $(\mathrm{n}=58$ [83\%]). Forty-two patients $(60 \%)$ met criteria for PLB. Fifty-one patients had monostotic disease, and 19 were discovered to have polyostotic disease. There was equal representation of patients with localized disease and patients with advanced disease with 35 patients in each category.

Patient OS was defined as the time from patient diagnosis to mortality from any cause. Date of death was confirmed in the Social Security Death Index [45]. Survival curves were formulated using the Kaplan-Meier method [30]. A log-rank test was used to compare survival between patient treatment groups. With the available sample size, it was estimated that a difference in survival of approximately $30 \%$ would have to be present for detection with $80 \%$ power $(\alpha=0.05, \beta=0.2, \mathrm{n}=70, \Delta=30 \%)$. Continuous variables were compared by independent t-test. Categorical variables were compared by chi square and Fisher's exact tests. Statistical analyses were completed in

Table 1. Primary versus secondary NHL of bone*

\begin{tabular}{|c|c|c|}
\hline Group & Description & Designation \\
\hline 1 & Monostotic disease with or without involvement of the regional nodes & PLB \\
\hline 2 & Polyostotic disease without involvement of the viscera or diffuse involvement of the lymph nodes & PLB \\
\hline 3 & $\begin{array}{l}\text { Diffuse lymph node involvement or involvement of the viscera is discovered in a patient presenting } \\
\text { with a bone tumor }\end{array}$ & SLB \\
\hline 4 & A patient with active or remote history of nonosseous lymphoma presents with a bone tumor & SLB \\
\hline
\end{tabular}

* Groups 1 and 2 are widely accepted to represent primary lymphoma of bone (PLB); Groups 3 and 4 are believed to represent secondary lymphoma of bone (SLB); NHL = non-Hodgkin's lymphoma. 
Table 2. Demographics and clinical characteristics by treatment groups

\begin{tabular}{|c|c|c|c|c|}
\hline Parameter & Total $(\mathrm{n}=70)$ & $\mathrm{CMT}(\mathrm{n}=24)$ & ST $(n=46)$ & $\mathrm{p}$ value \\
\hline Age, mean $\pm \mathrm{SD}$ (years) & $54 \pm 18$ & $56 \pm 17$ & $52 \pm 19$ & 0.505 \\
\hline \multicolumn{5}{|l|}{ Sex, number $(\%)$} \\
\hline Men & $42(60)$ & $13(54)$ & $29(63)$ & \multirow[t]{2}{*}{0.472} \\
\hline Women & $28(40)$ & $11(46)$ & $17(37)$ & \\
\hline \multicolumn{5}{|l|}{ Race/ethnicity, number (\%) } \\
\hline White & $49(70)$ & $15(63)$ & $34(74)$ & 0.323 \\
\hline Black & $9(13)$ & $3(13)$ & $6(13)$ & 0.632 \\
\hline Hispanic & $9(13)$ & $4(17)$ & $5(11)$ & 0.480 \\
\hline Other & $3(4)$ & $2(8)$ & $1(2)$ & 0.269 \\
\hline \multicolumn{5}{|l|}{ Histopathologic subtype, number (\%) } \\
\hline DLBCL & $58(83)$ & $19(79)$ & $39(85)$ & \multirow[t]{2}{*}{0.739} \\
\hline Indolent* & $12(17)$ & $5(21)$ & $7(15)$ & \\
\hline \multicolumn{5}{|l|}{ Tumor site, number (\%) } \\
\hline Weightbearing & 34 (49) & $15(63)$ & $19(41)$ & \multirow[t]{2}{*}{0.758} \\
\hline Nonweightbearing & $36(51)$ & $9(38)$ & $27(59)$ & \\
\hline \multicolumn{5}{|l|}{ Stage, number $(\%)$} \\
\hline Localized $^{\dagger}$ & $35(50)$ & $15(63)$ & $20(44)$ & \multirow[t]{2}{*}{0.131} \\
\hline Advanced $^{*}$ & $35(50)$ & $9(38)$ & $26(57)$ & \\
\hline \multicolumn{5}{|l|}{ Disease class, number $(\%)$} \\
\hline PLB & $42(60)$ & $15(63)$ & $27(59)$ & \multirow[t]{2}{*}{0.758} \\
\hline SLB & $28(40)$ & $9(38)$ & $19(41)$ & \\
\hline \multicolumn{5}{|l|}{ Systemic therapy, number (\%) } \\
\hline Anthracycline & $56(80)$ & $19(79)$ & $37(80)$ & 0.900 \\
\hline Rituximab & $56(80)$ & $21(88)$ & $35(76)$ & 0.352 \\
\hline Pretreatment fracture, number $(\%)$ & $21(30)$ & $5(21)$ & $16(35)$ & 0.227 \\
\hline Posttreatment fracture, number $(\%)$ & $5(7)$ & $5(21)$ & $0(0)$ & 0.004 \\
\hline
\end{tabular}

* Follicular lymphoma, marginal zone lymphoma, small lymphocytic lymphoma, Waldenström's macroglobulinemia; ${ }^{\dagger}$ monosotic disease with or without regional lymph node involvement (Ann Arbor Stages 1E and 2E); ${ }^{*}(1)$ polyostotic disease, (2) diffuse lymphadenopathy, (3) visceral involvement, or (4) bone marrow involvement; CMT = combined modality therapy; ST $=$ systemic therapy alone; DLBCL $=$ diffuse large B-cell lymphoma; PLB = primary lymphoma of bone; SLB = secondary lymphoma of bone.

SPSS (IBM Corporation, Armonk, NY, USA). Differences were considered significant for $\mathrm{p}$ values $<0.05$.

\section{Results}

With the data available, no difference in survival was observed at 5 or 10 years between patients treated with systemic therapy alone and those treated with CMT. Sixteen percent of the study population had died (11 of 70 patients) by the end of the study period with an average time-to-death of 120 months after diagnosis (range, 17$256 \pm 67$ months). The OS for the entire study population was $97 \%(95 \%$ confidence interval [CI], 92\%-100\%) at 5 years and $77 \%(95 \%$ CI, 59\%-95\%) at 10 years (Fig. 2A). In 46 patients treated with systemic therapy alone (66\% [46 of 70$])$, OS was $98 \%(95 \%$ CI, 93\%-100\%) at 5 years and $83 \%(95 \% \mathrm{CI}, 63 \%-100 \%)$ at 10 years. OS in 24 patients
(34\% [24 of 70]) who were treated with CMT was $95 \%$ $(95 \% \mathrm{CI}, 85 \%-100 \%)$ at 5 years and $71 \%$ (95\% CI, $42 \%-$ $100 \%$ ) at 10 years. No difference in survival was observed between treatment groups ( $\mathrm{p}=0.281$; Fig. $2 \mathrm{~B}$ ). Independent analysis was carried out for 42 patients with PLB (60\% [42 of 70]); OS was 97\% (95\% CI, 91\%-100\%) at 5 years and $89 \%(95 \% \mathrm{CI}, 73 \%-100 \%)$ at 10 years and survival did not differ between treatment groups ( $\mathrm{p}=0.953$; Fig. 2C-D).

A proportionate number of patients in each group presented with pathologic fractures; however, problems with fracture healing were more prevalent in those treated with radiation (Table 4). Fracture at presentation was observed in $35 \%$ (16 of 46) treated with systemic therapy alone and $21 \%$ (five of 24 ) treated with CMT ( $\mathrm{p}=0.227$ ). Surgical stabilization was attempted in $38 \%$ of those treated without radiation (six of 16) and $20 \%$ (one of five) of those treated with CMT. Abnormal fracture healing was observed in $6 \%$ 


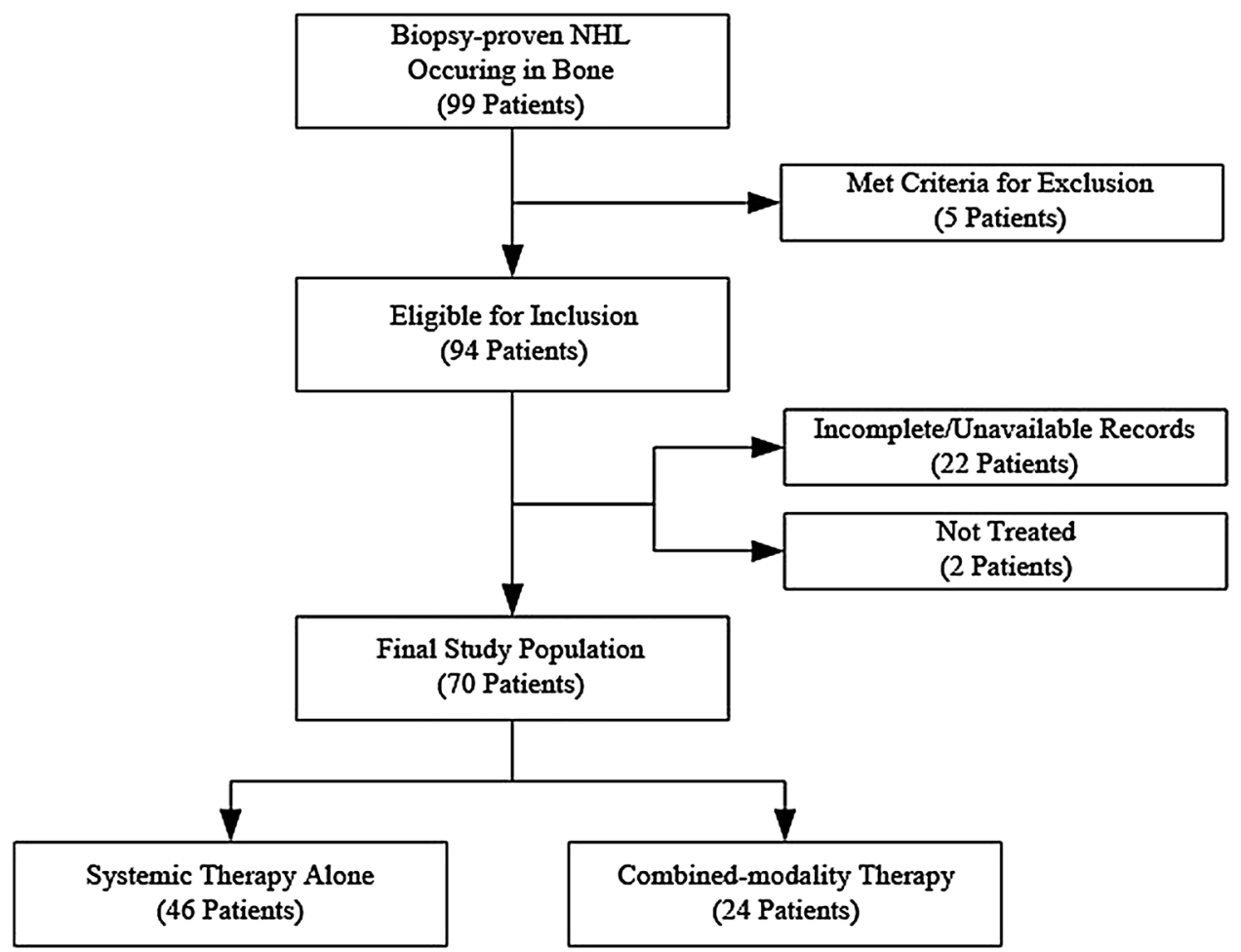

Fig. 1 Ninety-nine patients with newly diagnosed lymphoma of bone were screened. The final study population included 70 patients.

Table 3. Distribution of biopsy sites in 70 patients with NHL of bone

\begin{tabular}{lcc}
\hline Bone & Number & Percent \\
\hline Femur & 21 & 30 \\
Humerus & 12 & 17 \\
Pelvis & 9 & 13 \\
Tibia & 6 & 9 \\
Scapula & 6 & 9 \\
Spine & 6 & 9 \\
Clavicle & 3 & 4 \\
Skull & 2 & 3 \\
Radius & 2 & 3 \\
Foot & 2 & 3 \\
Fibula & 1 & 1 \\
\hline
\end{tabular}

NHL = non-Hodgkin's lymphoma.

(one of 16) unexposed to radiation and $80 \%$ (four of five; Fig. 3) irradiated at the site of disease (relative risk [RR], 12.8; 95\% CI 1.8-89.8; $\mathrm{p}=0.01$ ).

Treatment with radiation was also associated with risk for secondary fracture and abnormal fracture healing (Table 5). Patients treated with radiation had a greater risk of sustaining fractures in the posttreatment period (five of 24 versus no radiation zero of 46; RR, 20.7; 95\% CI, $1.2-$ $359.0 ; \mathrm{p}=0.0375)$. Surgical stabilization was attempted in $60 \%$ (three of five) after fracture. Most displayed abnormal fracture healing including delayed union, nonunion, and malunion (Figs. 4, 5). It cannot be confirmed from the data, however, that these complications occurred as a result of radiation exposure rather than from errors in patient management or the result of patient factors (eg, low bone density).

Functional outcomes data indicated that patients treated with radiation experienced poorer outcomes than those treated without radiation (Table 6). Mean MSTS score in 33 patients $(73 \%)$ treated with systemic therapy alone was $91 \%$ and $75 \%$ in $12(27 \%)$ patients treated with CMT $(\mathrm{p}=0.034)$. Seven patients (16\% [seven of 45]) experienced secondary complications (six of the patients were in the radiationtreated group) and reported poorer outcomes compared with patients who did not have complications after treatment $(\mathrm{p}=0.007)$. Outcomes did not differ between the treatment groups based on limb involvement or fracture at presentation ( $\mathrm{p}=0.093, \mathrm{p}=0.887$, respectively).

\section{Discussion}

Management of patients with NHL of bone has changed over time. Treating patients with surgical resection has fallen out of favor in light of superior survivorship with nonoperative therapies, including radiation, chemotherapy, and the addition of rituximab [43]. The role of 

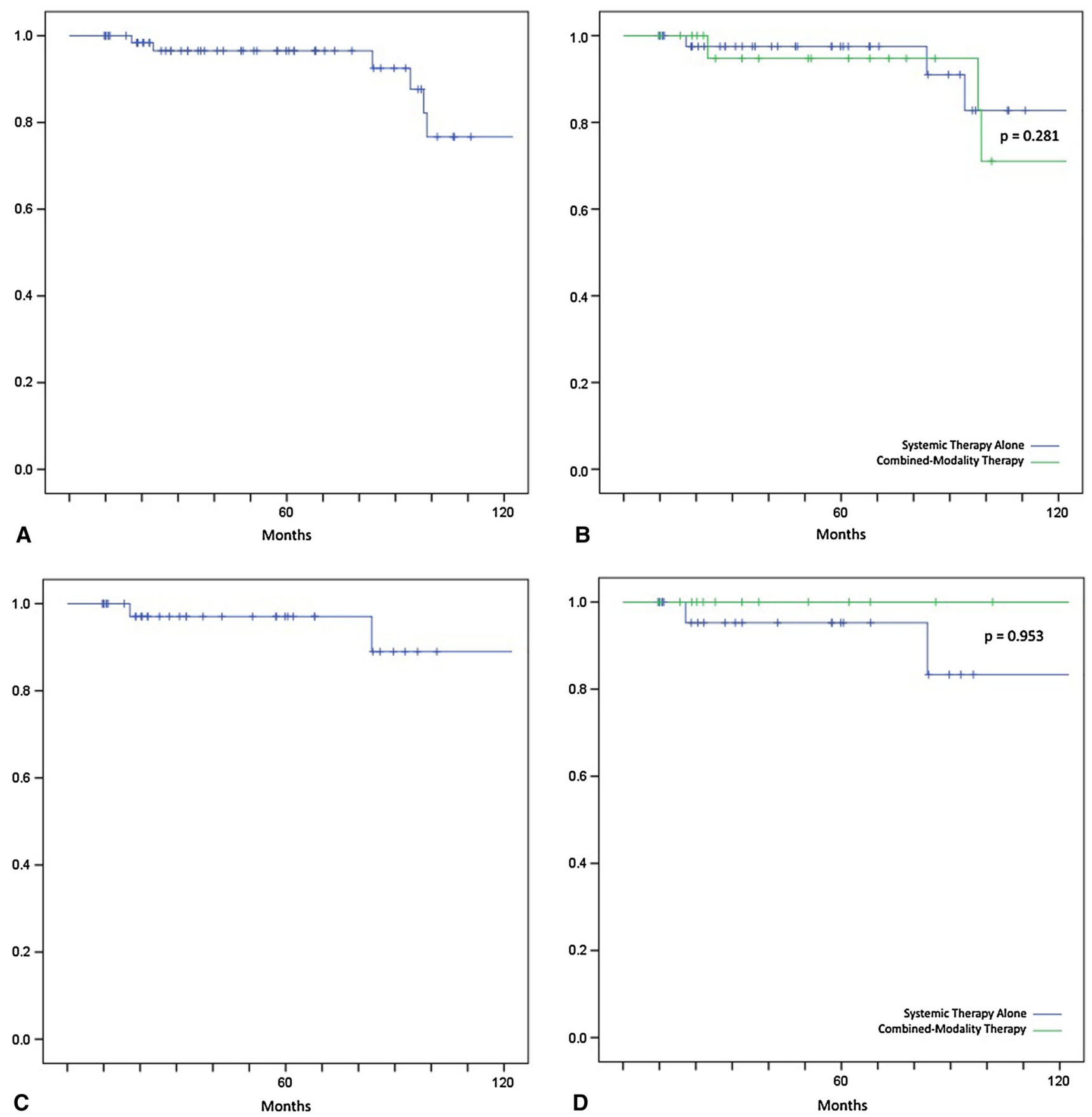

Fig. 2A-D (A) Kaplan-Meier survival curve depicting the overall survival for the entire study population. The vertical lines represent censored data. (B) Kaplan-Meier survival curves demonstrating overall survival in all patients treated with systemic therapy alone (blue) and combined modality therapy (green). The vertical lines represent censored data. (C) Kaplan-Meier survival curve depicting

radiotherapy, however, has come under scrutiny as recent studies have demonstrated excellent clinical outcomes in its absence $[1,9,12,36,41]$. The natural history of NHL of bone is incompletely understood, and patient functional outcomes after treatment have not been well studied. We

the overall survival for 42 patients with primary non-Hodgkin's lymphoma of bone (PLB). The vertical lines represent censored data. (D) Kaplan-Meier survival curve demonstrating overall survival in patients with primary non-Hodgkin's lymphoma of bone (PLB) treated with systemic therapy alone (blue) and combined modality therapy (green). The vertical lines represent censored data.

retrospectively examined patients with NHL of bone diagnosed at our tertiary care institution during a 28 -year period. We failed to observe a clear survival advantage in patients treated with radiotherapy and observed a high rate of orthopaedic complications occurring in patients treated 
Table 4. Pretreatment complications

\begin{tabular}{|c|c|c|c|c|c|c|c|c|c|c|}
\hline $\begin{array}{l}\text { Patient } \\
\text { number }\end{array}$ & $\begin{array}{l}\text { Age } \\
\text { (years)/ } \\
\text { sex }\end{array}$ & Site & $\begin{array}{l}\text { Pretreatment } \\
\text { complication(s) }\end{array}$ & Surgery & $\begin{array}{l}\text { Surgical } \\
\text { procedure }\end{array}$ & $\begin{array}{l}\text { Treatment } \\
\text { group }\end{array}$ & $\begin{array}{l}\text { Secondary } \\
\text { complications }\end{array}$ & $\begin{array}{l}\text { Followup } \\
\text { (months) }\end{array}$ & $\begin{array}{l}\text { Patient } \\
\text { status }\end{array}$ & $\begin{array}{l}\text { MSTS } \\
\text { score } \\
(\%)\end{array}$ \\
\hline 1 & $66 / \mathrm{F}$ & Scapula & Fracture & No & N/A & ST & $\begin{array}{l}\text { Displacement, } \\
\text { nonunion }\end{array}$ & 11 & Alive & 57 \\
\hline 2 & 64/M & Humerus & Fracture & Yes & Intramedullary nail & ST & None & 10 & Alive & 97 \\
\hline 3 & $51 / \mathrm{M}$ & Pelvis & Fracture & No & N/A & ST & None & 10 & Alive & 100 \\
\hline 4 & $53 / \mathrm{M}$ & Spine & $\begin{array}{l}\text { Fracture, compressive } \\
\text { myelopathy }\end{array}$ & Yes & Laminectomy & ST & None & 19 & Alive & N/A \\
\hline 5 & $69 / \mathrm{M}$ & Femur & Fracture & No & N/A & CMT & Delayed union & 16 & Alive & 80 \\
\hline 6 & $66 / \mathrm{F}$ & Humerus & Fracture & No & N/A & ST & None & 31 & Alive & 97 \\
\hline 7 & $72 / \mathrm{M}$ & Scapula & Fracture & No & N/A & ST & None & 33 & Alive & 90 \\
\hline 8 & $16 / \mathrm{M}$ & Femur & Fracture & No & N/A & ST & None & 43 & Alive & 93 \\
\hline 9 & 76/M & Femur & $\begin{array}{l}\text { Degenerative joint } \\
\text { disease }\end{array}$ & Yes & THA & ST & None & 48 & Alive & 87 \\
\hline 10 & $41 / M$ & Clavicle & Fracture & No & N/A & ST & None & 57 & Alive & 100 \\
\hline 11 & $46 / M$ & Radius & Fracture & No & N/A & CMT & Malunion & 62 & Alive & 100 \\
\hline 12 & $64 / \mathrm{M}$ & Scapula & Fracture & No & N/A & ST & None & 62 & Alive & 100 \\
\hline 13 & $59 / \mathrm{M}$ & Spine & Fracture & Yes & Corpectomy, fusion & ST & None & 68 & Alive & N/A \\
\hline 14 & $78 / \mathrm{F}$ & Fibula & Fracture & No & N/A & ST & None & 68 & Alive & 87 \\
\hline 15 & $48 / \mathrm{F}$ & Femur & Fracture & Yes & THA & ST & $\begin{array}{l}\text { Revision } \\
\quad \text { arthroplasty }\end{array}$ & 17 & Deceased & N/A \\
\hline 16 & $55 / \mathrm{M}$ & Spine & Fracture & Yes & Corpectomy, fusion & ST & None & 84 & Alive & N/A \\
\hline 17 & $79 / \mathrm{F}$ & Femur & Fracture & Yes & Intramedullary nail & CMT & Nonunion & 86 & Alive & 40 \\
\hline 18 & $65 / \mathrm{M}$ & Humerus & Fracture & No & N/A & ST & None & 97 & Alive & 100 \\
\hline 19 & $62 / \mathrm{F}$ & Femur & Osteonecrosis & Yes & Core decompression & ST & None & 103 & Alive & 93 \\
\hline 20 & $59 / \mathrm{M}$ & Femur & Osteonecrosis & Yes & Core decompression & ST & None & 111 & Alive & No response \\
\hline 21 & $58 / \mathrm{M}$ & Spine & $\begin{array}{l}\text { Compressive } \\
\text { myelopathy }\end{array}$ & Yes & Laminectomy & CMT & None & 23 & Deceased & N/A \\
\hline 22 & $60 / \mathrm{M}$ & Pelvis & Fracture & No & N/A & CMT & None & 55 & Deceased & N/A \\
\hline 23 & $65 / \mathrm{F}$ & Spine & Fracture & No & N/A & ST & None & 150 & Alive & N/A \\
\hline 24 & $75 / \mathrm{F}$ & Humerus & Fracture & No & N/A & CMT & Nonunion & 54 & Deceased & N/A \\
\hline 25 & $73 / \mathrm{F}$ & Femur & Fracture & Yes & THA & ST & None & 144 & Deceased & N/A \\
\hline
\end{tabular}

MSTS = Musculoskeletal Tumor Society; F = female; $\mathrm{M}=$ male; N/A = not applicable; ST = systemic therapy alone; CMT $=$ combined modality therapy; THA $=$ total hip arthroplasty.

with radiation. In addition, we present functional assessment of patients treated for NHL of bone and show inferior functional outcomes in patients treated with radiation.

Our study had several limitations. First, selection bias must be considered when interpreting our results due to the retrospective nature of the study and our inability to randomly assign patients to treatment groups. Treatment selection was strongly influenced by disease stage, patient factors (eg, poor tolerance of chemotherapy), and clinician preference. In general, consolidative radiotherapy is favored in patients with localized disease to prevent local treatment failure but may also be administered to patients with advanced disease if the primary site of disease is bulky $[17,44]$. Second, substantial risk remains for type II error (the inability to observe a true difference in survival between the treatment groups), despite the relatively large study population. With the present sample size, a difference in survival of approximately $30 \%$ would have had to be present for detection with $80 \%$ power. Third, four patients did not meet the minimum followup requirement of 6 months and were excluded from the study. More significantly, 22 patients, the majority of whom were diagnosed early during the study period, could not be analyzed because of incomplete or unavailable records.

We compared survival outcomes between two statistically similar groups of patients completing treatment with systemic therapy alone or CMT. We observed excellent survival outcomes in both groups and failed to observe a significant survival advantage with radiotherapy. Instead, we observed an increased risk for bony complications in patients treated with radiation. Survival outcomes were similar when analysis was restricted to patients with PLB. Similar to earlier studies involving patients with NHL of bone, we observed a male predominance, a predisposition 


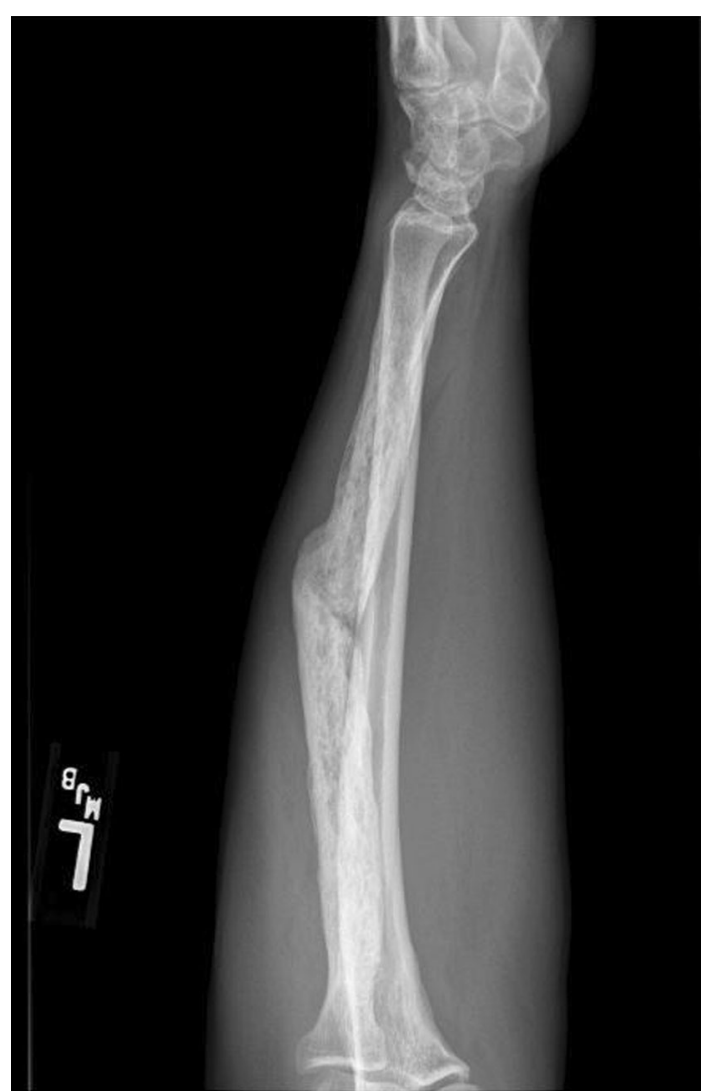

Fig. 3 Malunion of the radius in a 46-year-old man who presented with a large forearm mass and pathologic midshaft radius fracture is shown. The patient was diagnosed with primary DLBCL of the left radius and treated with $\mathrm{R}-\mathrm{CHOP}$ for six cycles followed by consolidative radiotherapy.

for older adults, and a predilection for involvement of long bones with the disease $[1,29]$. We confirmed DLBCL to be the most common histopathologic variant and verified pain as the most common presenting symptom [1, 2, 22, 23]. Early studies concerning bone lymphoma highlighted the integral role of systemic therapy and the insufficiency of monotherapy with radiation or surgery [3, 21, 53]. The efficacy of radiation as an adjunct came under question in lieu of recent studies demonstrating excellent survival outcomes with systemic therapy alone, particularly with the addition of rituximab [1, 12, 13, 41]. Several studies, however, have continued to support the continued use of radiation combined with chemotherapy in adults (CMT) [5, 14, 28, 40].

Management of patients with NHL of bone has become largely nonoperative, but surgical intervention remains critical in the management of disease-related complications as well as complications associated with treatment. We observed a high rate of bony complications occurring at patient presentation with a pathologic fracture rate of $30 \%$ and overall orthopaedic complication rate of $36 \%$. Roughly half of the patients required operative care and just more

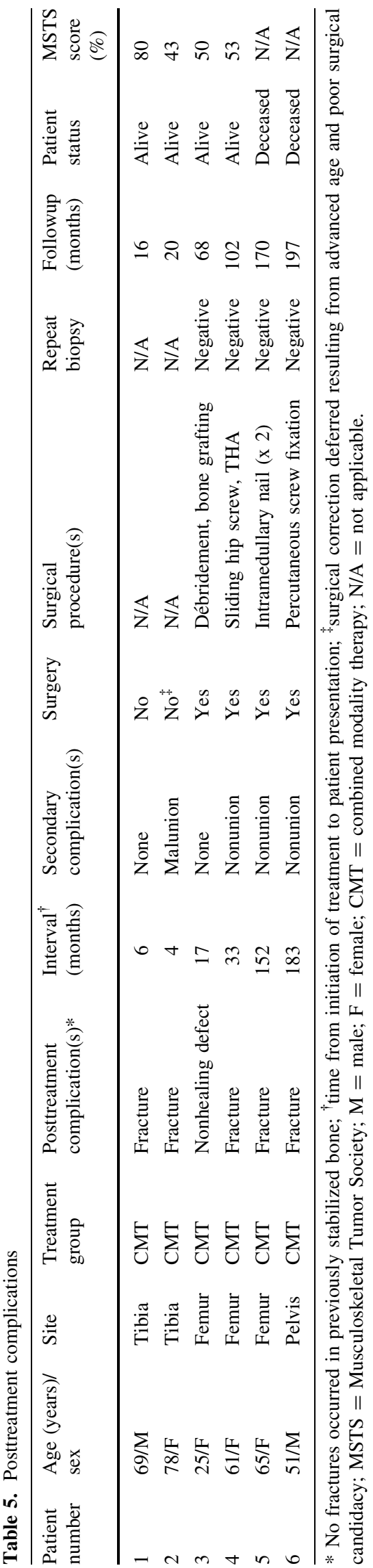




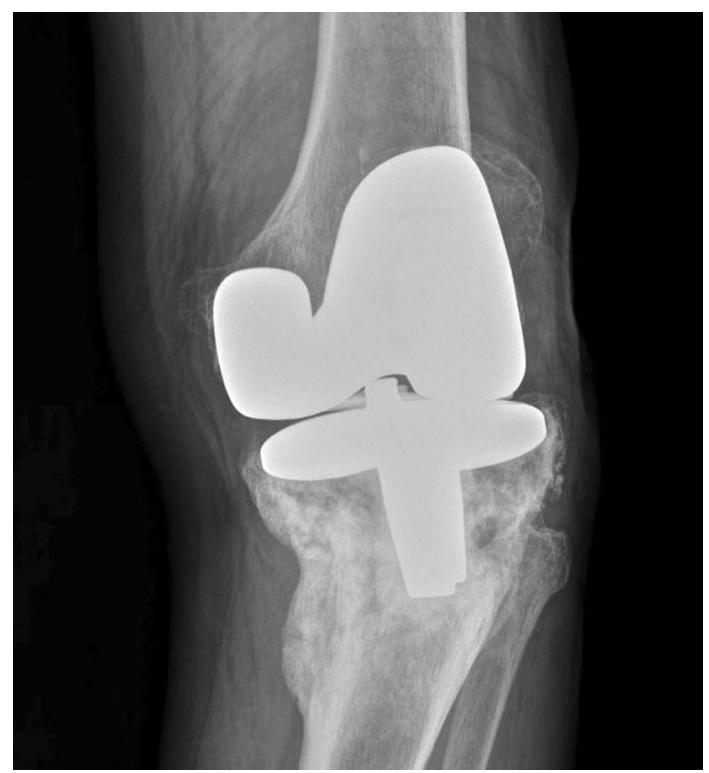

Fig. 4 Primary DLBCL of the proximal tibia in a 78-year-old woman who had undergone ipsilateral TKA is shown. The patient was treated with combined modality therapy and sustained a posttreatment fracture of the proximal tibia, which was further complicated by varus malunion. Knee reconstruction was deferred as a result of poor surgical candidacy.

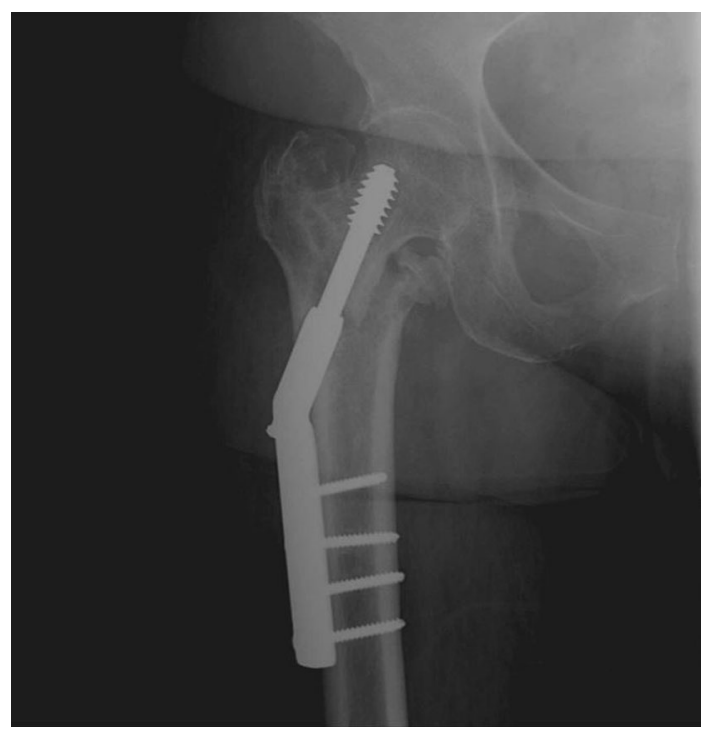

Fig. 5 Posttreatment fracture in a 61-year-old woman originally diagnosed with primary DLBCL of the proximal femur is shown. The patient was treated with four cycles of R-CHOP followed by consolidative radiotherapy. The fracture failed to unite after stabilization with a sliding hip screw resulting in collapse and eventual conversion to THA.

than one-third of patients presenting with fractures were stabilized surgically. Nonoperative management of selected fractures, however, did permit successful healing once oncologic care had been initiated. Conversely, fracture displacement and irradiation of the fracture site were associated with abnormal fracture healing, including delayed union, malunion, and nonunion. Radiation-related alterations in fracture healing, including poor progression between the biomechanical stages of healing and a higher susceptibility to failure in torsion, have been demonstrated in animal models $[8,35,38]$. Prolonged healing times and high rates of nonunion after radiotherapy have also been demonstrated in patients undergoing treatment for soft tissue malignancies [27, 32]. As an additional consequence, the inertness of the irradiated bone creates challenges in achieving operative fixation [10]. As such, advanced surgical techniques, including fracture site resection and grafting, are often necessary to achieve union [10].

We also observed a high rate of bony complications arising later in the disease course and occurring predominantly in patients treated with radiation. A significant relationship was observed between treatment with radiotherapy and the occurrence of posttreatment fractures, which supports earlier studies demonstrating an increased risk of fracture in patients with NHL of bone, who were treated with radiation, particularly in high doses [33, 46]. Other studies have also shown fractures to occur multiple years after radiation treatment and some investigators have suggested that fracture risk does not decrease over time [4, $26,31,37]$. Risk of fracture in our study did not appear to be related to the age or sex of the patient. Each fracture occurred in a weightbearing bone, although the distribution of weightbearing lesions was similar between the irradiated and nonirradiated cohorts. Once again, we observed a troublesome pattern of suboptimal bone healing with the majority of patients undergoing surgical intervention. Long-term disability was observed in these patients and in patients with pretreatment fractures who experienced difficulties with healing. Given the debated use of radiotherapy, we have concerns that such complications may represent unnecessary patient morbidity. It may be reasonable to avoid radiation and the associated complications in the treatment of NHL of bone. Alternatively, lower doses of radiation or different strategies for delivery may lessen these complications.

We have provided the first functional assessment of patients treated for NHL occurring in bone and demonstrated outstanding functional outcomes for patients in the absence of bony complications. The majority of patients achieved an "excellent" outcome with many reporting a perfect score at final followup. Pain often resolved within weeks of initiating systemic therapy and outcomes did not differ by disease site. Notably, we observed no difference in outcomes of patients presenting with pathologic fractures and patients presenting without fracture. Poorer outcomes, however, were observed in responding patients who had experienced secondary complications, the 
Table 6. Functional outcomes

\begin{tabular}{|c|c|c|c|c|}
\hline Group, subgroup & Number $(\%)$ & MSTS score & MSTS score $(\%)^{*}$ & $\mathrm{p}$ value \\
\hline All patients & $45(100)$ & $26 \pm 5$ & $87 \pm 16$ & N/A \\
\hline \multicolumn{5}{|l|}{ Treatment group } \\
\hline ST & $33(73)$ & $27 \pm 3$ & $91 \pm 10$ & \multirow[t]{2}{*}{0.034} \\
\hline CMT & $12(27)$ & $23 \pm 7$ & $75 \pm 23$ & \\
\hline \multicolumn{5}{|l|}{ Limb involvement } \\
\hline Upper extremity & $18(40)$ & $28 \pm 4$ & $92 \pm 12$ & \multirow[t]{2}{*}{0.093} \\
\hline Lower extremity & $27(60)$ & $25 \pm 5$ & $84 \pm 18$ & \\
\hline \multicolumn{5}{|c|}{ Fracture at presentation } \\
\hline Fracture & $14(31)$ & $26 \pm 6$ & $86 \pm 19$ & \multirow[t]{2}{*}{0.887} \\
\hline No fracture & $31(69)$ & $26 \pm 5$ & $87 \pm 15$ & \\
\hline \multicolumn{5}{|c|}{ Secondary complications* } \\
\hline Complicated $^{\dagger}$ & $7(16)$ & $18 \pm 6$ & $60 \pm 21$ & \multirow[t]{2}{*}{0.007} \\
\hline Uncomplicated & $38(84)$ & $28 \pm 2$ & $92 \pm 8$ & \\
\hline
\end{tabular}

* Secondary complications included those occurring during management of pre-treatment complications and complications arising in the posttreatment period; ${ }^{\dagger}$ secondary complications occurred in seven patients (six treated with radiation) and included posttreatment fracture with abnormal healing (3), nonunion of pretreatment fracture (2), malunion of pretreatment fracture (1), and nonhealing defect requiring debridement and graft placement (1); ${ }^{*}$ mean \pm SD.

MSTS = Musculoskeletal Tumor Society; ST = systemic therapy alone; CMT = combined modality therapy; N/A = not applicable.

majority of which occurred in patients treated with radiation. Our results suggest that patients with NHL of bone can be reasonably expected to return to a premorbid level of function after an uncomplicated treatment course. Because there was no observable benefit from receiving radiotherapy with respect to survival with the numbers we had in this study, it might be reasonable to conduct larger, prospective studies assessing whether radiation is necessary in treatment of patients with NHL of bone.

Several topics of interest in patients with lymphoma of bone were not examined in this study. Local disease recurrence has been a key subject of interest in these patients, and its prevention has been the primary rationale for consolidative radiotherapy. Interestingly, studies investigating this endpoint, primarily in patients with PLB, have consistently demonstrated the site of relapse to be distant from the original site of disease. In fact, local disease failure appears to be a rare phenomenon irrespective of treatment with radiation [42]. These findings have supported rising skepticisms regarding the essentialness of radiotherapy, particularly in the era of rituximab. Similarly, guidelines for disease surveillance in patients with lymphoma of bone are not well established. Integrated PET-CT has emerged as the imaging modality of choice in patients with fluorodeoxyglucose-avid tumors including most subtypes of lymphoma [52]. Previously, and during the earlier portion of our study period, gallium scintigraphy routinely complemented traditional CT evaluation for staging, response assessment, and surveillance. The optimal frequency of surveillance scans is controversial [48]. Reassessment with plain radiographs and PET may suggest relapse (or complication) in patients with recurrent symptoms; however, repeat biopsy is the only means of definitely proving recurrence.

In conclusion, patient clinical outcomes following treatment for NHL of bone are excellent with contemporary therapies. The survival benefit of radiation use, however, remains debatable. Patient functional outcomes are similarly excellent in the absence of complications that have been associated with radiation. We suggest that further study regarding the necessity of radiation in treatment of lymphoma of bone be conducted in larger, prospective studies.

Acknowledgments We thank the Pathology, Hematology, Medical Oncology, and Radiation Oncology Departments at Rush University Medical Center, Chicago, IL, USA.

\section{References}

1. Alencar A, Pitcher D, Byrne G, Lossos IS. Primary bone lymphoma-the University of Miami experience. Leuk Lymphoma. 2010;1:39-49.

2. Baar J, Burkes RL, Bell R, Blackstein ME, Fernandes B, Langer F. Primary non-Hodgkin's lymphoma of bone. A clinicopathologic study. Cancer. 1994;4:1194-1199.

3. Barbieri E, Cammelli S, Mauro F, Perini F, Cazzola A, Neri S, Bunkheila F, Ferrari S, Brandoli V, Zinzani P, Mercuri M, Bacci G. Primary non-Hodgkin's lymphoma of the bone: treatment and analysis of prognostic factors for stage I and stage II. Int J Radiat Oncol Biol Phys. 2004;3:760-764.

4. Baxter NN, Habermann EB, Tepper JE, Durham SB, Virnig BA. Risk of pelvic fractures in older women following pelvic irradiation. JAMA. 2005;20:2587-2593. 
5. Beal K, Allen L, Yahalom J. Primary bone lymphoma: treatment results and prognostic factors with long-term follow-up of 82 patients. Cancer. 2006;12:2652-2656.

6. Bhandari M, Fong K, Sprague S, Williams D, Petrisor B. Variability in the definition and perceived causes of delayed unions and nonunions: a cross-sectional, multinational survey of orthopaedic surgeons. J Bone Joint Surg Am. 2012;15: e1091-e1096.

7. Bluemke DA, Fishman EK, Scott WW Jr. Skeletal complications of radiation therapy. Radiographics. 1994;1:111-121.

8. Bonarigo BC, Rubin P. Nonunion of pathologic fracture after radiation therapy. Radiology. 1967;5:889-898.

9. Bonnet C, Fillet G, Mounier N, Ganem G, Molina TJ, Thieblemont C, Ferme C, Quesnel B, Martin C, Gisselbrecht C, Tilly H, Reyes F, Groupe d'Etude des Lymphomes de l'Adulte. CHOP alone compared with $\mathrm{CHOP}$ plus radiotherapy for localized aggressive lymphoma in elderly patients: a study by the groupe d'etude des lymphomes de l'adulte. J Clin Oncol. 2007;7:787-792.

10. Cannon CP, Lin PP, Lewis VO, Yasko AW. Management of radiation-associated fractures. $J$ Am Acad Orthop Surg. 2008;9:541-549.

11. Carbone PP, Kaplan HS, Musshoff K, Smithers DW, Tubiana M. Report of the committee on Hodgkin's disease staging classification. Cancer Res. 1971;11:1860-1861.

12. Catlett JP, Williams SA, O'Connor SC, Krishnan J, Malkovska V. Primary lymphoma of bone: an institutional experience. Leuk Lymphoma. 2008;11:2125-2132.

13. Charousset C, Anract P, Carlioz B, Babinet A, Tomeno B. Primary bone lymphoma. Retrospective immunohistochemical study of 22 cases. Rev Chir Orthop Reparatrice Appar Mot. 2002;5: 439-448.

14. Christie D, Dear K, Le T, Barton M, Wirth A, Porter D, Roos D, Pratt G. Limited chemotherapy and shrinking field radiotherapy for osteolymphoma (primary bone lymphoma): results from the trans-Tasman Radiation Oncology Group 99.04 and Australasian Leukaemia and Lymphoma Group LY02 prospective trial. Int J Radiat Oncol Biol Phys. 2011;4:1164-1170.

15. de Camargo OP, dos Santos Machado TM, Croci AT, de Oliveira CR, Giannotti MA, Baptista AM, Caiero MT, Alves VA, Matsumoto LA. Primary bone lymphoma in 24 patients treated between 1955 and 1999. Clin Orthop Relat Res. 2002;397:271-280.

16. Demircay E, Hornicek FJ Jr, Mankin HJ, Degroot H 3rd. Malignant lymphoma of bone: a review of 119 patients. Clin Orthop Relat Res. 2013;471:2684-2690.

17. Dorth JA, Prosnitz LR, Broadwater G, Diehl LF, Beaven AW, Coleman RE, Kelsey CR. Impact of consolidation radiation therapy in stage III-IV diffuse large B-cell lymphoma with negative post-chemotherapy radiologic imaging. Int $J$ Radiat Oncol Biol Phys. 2012;3:762-767.

18. Economedes DM, Abzug JM, Paryavi E, Herman MJ. Outcomes using titanium elastic nails for open and closed pediatric tibia fractures. Orthopedics. 2014;7:e619-e624.

19. Elliott SP, Jarosek SL, Alanee SR, Konety BR, Dusenbery KE, Virnig BA. Three-dimensional external beam radiotherapy for prostate cancer increases the risk of hip fracture. Cancer. 2011;19:4557-4565.

20. Enneking WF, Dunham W, Gebhardt MC, Malawar M, Pritchard DJ. A system for the functional evaluation of reconstructive procedures after surgical treatment of tumors of the musculoskeletal system. Clin Orthop Relat Res. 1993;286:241-246.

21. Fairbanks RK, Bonner JA, Inwards CY, Strickler JG, Habermann TM, Unni KK, Su J. Treatment of stage IE primary lymphoma of bone. Int J Radiat Oncol Biol Phys. 1994;2:363-372.

22. Fidias P, Spiro I, Sobczak ML, Nielsen GP, Ruffolo EF, Mankin H, Suit HD, Harmon DC. Long-term results of combined modality therapy in primary bone lymphomas. Int J Radiat Oncol Biol Phys. 1999;5:1213-1218.

23. Gianelli U, Patriarca C, Moro A, Ponzoni M, Giardini R, Massimino M, Alfano RM, Armiraglio E, Nuciforo P, Bosari S, Coggi G, Parafioriti A. Lymphomas of the bone: a pathological and clinical study of 54 cases. Int J Surg Pathol. 2002;4:257-266.

24. Glotzbecker MP, Kersun LS, Choi JK, Wills BP, Schaffer AA, Dormans JP. Primary non-Hodgkin's lymphoma of bone in children. J Bone Joint Surg Am. 2006;3:583-594.

25. Green DE, Adler BJ, Chan ME, Rubin CT. Devastation of adult stem cell pools by irradiation precedes collapse of trabecular bone quality and quantity. J Bone Miner Res. 2012;4:749-759.

26. Hatano H, Morita T, Kobayashi H, Ito T, Segawa H, Saito M. Pathological fracture of the femur ten years after successful radiation therapy for metastatic breast cancer. Breast Cancer. 2004;3:313-317.

27. Helmstedter CS, Goebel M, Zlotecki R, Scarborough MT. Pathologic fractures after surgery and radiation for soft tissue tumors. Clin Orthop Relat Res. 2001;389:165-172.

28. Huang JJ, Xia Y, Zhu YJ, Lin TY, Li ZM, Jiang WQ, Xu RH, Huang HQ, Lv Y, Sun XF, Xia ZJ. Clinical characterization and prognostic factors of primary lymphoma of bone in case of Chinese patients. Med Oncol. 2011:S476-S482.

29. Jawad MU, Schneiderbauer MM, Min ES, Cheung MC, Koniaris LG, Scully SP. Primary lymphoma of bone in adult patients. Cancer. 2010;4:871-879.

30. Kaplan EL, Meier P. Nonparametric estimation from incomplete observations. J Am Stat Assoc. 1958:457-481.

31. Kwon JW, Huh SJ, Yoon YC, Choi SH, Jung JY, Oh D, Choe BK. Pelvic bone complications after radiation therapy of uterine cervical cancer: evaluation with MRI. AJR Am J Roentgenol. 2008;4:987-994.

32. Lin PP, Boland PJ, Healey JH. Treatment of femoral fractures after irradiation. Clin Orthop Relat Res. 1998;352:168-178.

33. Lucraft HH. Primary lymphoma of bone: a review of 13 cases emphasizing orthopaedic problems. Clin Oncol (R Coll Radiol). 1991;5:265-269.

34. Magnus HA, Wood HL. Primary reticulo-sarcoma of bone. $J$ Bone Joint Surg Br. 1956;1:258-278.

35. Markbreiter LA, Pelker RR, Friedlaender GE, Peschel R, Panjabi MM. The effect of radiation on the fracture repair process. A biomechanical evaluation of a closed fracture in a rat model. $J$ Orthop Res. 1989;2:178-183.

36. Miller TP, Dahlberg S, Cassady JR, Adelstein DJ, Spier CM, Grogan TM, LeBlanc M, Carlin S, Chase E, Fisher RI. Chemotherapy alone compared with chemotherapy plus radiotherapy for localized intermediate- and high-grade non-hodgkin's lymphoma. N Engl J Med. 1998;1:21-26.

37. Niikura T, Lee SY, Sakai Y, Nishida K, Kuroda R, Kurosaka M. Radiation-associated fracture nonunion of the clavicle treated with locking plate fixation and autologous bone grafting. Case Rep Med. 2012:407349.

38. Pelker RR, Friedlaender GE, Panjabi MM, Kapp D, Doganis A. Radiation-induced alterations of fracture healing biomechanics. $J$ Orthop Res. 1984;1:90-96.

39. Pellegrini C, Gandolfi L, Quirini F, Ruggieri P, Stefoni V, Derenzini E, Broccoli A, Argnani L, Pileri S, Mercuri M, Baccarani M, Zinzani PL. Primary bone lymphoma: evaluation of chemoimmunotherapy as front-line treatment in 21 patients. Clin Lymphoma Myeloma Leuk. 2011;4:321-325.

40. Power DG, McVey GP, Korpanty G, Treacy A, Dervan P, O'Keane C, Carney DN. Primary bone lymphoma: single institution case series. Ir J Med Sci. 2008;3:247-251.

41. Ramadan KM, Shenkier T, Sehn LH, Gascoyne RD, Connors JM. A clinicopathological retrospective study of 131 patients with 
primary bone lymphoma: a population-based study of successively treated cohorts from the British Columbia Cancer Agency. Ann Oncol. 2007;1:129-135.

42. Reddy N, Greer JP. Primary bone lymphoma: a set of unique problems in management. Leuk Lymphoma. 2010;1:1-2.

43. Scoccianti G, Rigacci L, Puccini B, Campanacci DA, Simontacchi G, Bosi A, Capanna R. Primary lymphoma of bone: outcome and role of surgery. Int Orthop. 2013;12:2437-2442.

44. Shipp MA, Klatt MM, Yeap B, Jochelson MS, Mauch PM, Rosenthal DS, Skarin AT, Canellos GP. Patterns of relapse in large-cell lymphoma patients with bulk disease: implications for the use of adjuvant radiation therapy. J Clin Oncol. 1989;5:613-618.

45. Social Security Death Index. 2014. Available at: http://ssdi. rootsweb.ancestry.com. Accessed August 28, 2014.

46. Stokes SH, Walz BJ. Pathologic fracture after radiation therapy for primary non-Hodgkin's malignant lymphoma of bone. Int J Radiat Oncol Biol Phys. 1983;8:1153-1159.

47. Taylor J. Delayed union and nonunion of fractures. In: Crenshaw A, ed. Campbell's Operative Orthopaedics. 8th ed. St Louis, MO, USA: Mosby; 1992:1287-1345.

48. Thompson CA, Ghesquieres H, Maurer MJ, Cerhan JR, Biron P, Ansell SM, Chassagne-Clement C, Inwards DJ, Gargi T, Johnston PB, Nicolas-Virelizier E, Macon WR, Peix M, Micallef IN,
Sebban C, Nowakowski GS, Porrata LF, Weiner GJ, Witzig TE, Habermann TM, Link BK. Utility of routine post-therapy surveillance imaging in diffuse large B-cell lymphoma. J Clin Oncol. 2014;31:3506-3512.

49. Unni K, Hongendoorn P. Malignant lymphoma. In: Fletcher C, Unni K, Mertens F, eds. Pathology and Genetics of Tumours of Soft Tissue and Bone. Lyon, France: IARC Press; 2002:306308.

50. Valls J, Muscolo D, Schajowicz F. Reticulum-cell sarcoma of bone. J Bone Joint Surg Br. 1952;4:588-598.

51. Wernle JD, Damron TA, Allen MJ, Mann KA. Local irradiation alters bone morphology and increases bone fragility in a mouse model. J Biomech. 2010;14:2738-2746.

52. Wirth A, Seymour JF, Hicks RJ, Ware R, Fisher R, Prince M, MacManus MP, Ryan G, Januszewicz H, Wolf M. Fluorine-18 fluorodeoxyglucose positron emission tomography, gallium-67 scintigraphy, and conventional staging for Hodgkin's disease and non-Hodgkin's lymphoma. Am J Med. 2002;4:262-268.

53. Zinzani PL, Carrillo G, Ascani S, Barbieri E, Tani M, Paulli M, Stefoni V, Sabattini E, Alinari L, Binazzi R, Tura S, Baccarani M, Pileri SA. Primary bone lymphoma: experience with 52 patients. Haematologica. 2003;3:280-285. 